\title{
COMPUTATIONAL TESTING OF WEAR RATE OF DIFFERENT MATERIAL WITH VARIABLE OPERATING PARAMETERS
}

\author{
Manoj Sahebrao Hajare ${ }^{1}$, Kiran Suresh Deore ${ }^{2}$, Lalita Mahadev Aage ${ }^{3}$ \\ ${ }^{1}$ Assistant Professor, SITRC,Sandip Foundation,Nashik \\ ${ }^{2}$ Students of SITRC, Sandip Foundation, Nashik \\ ${ }^{3}$ Students of SITRC, Sandip Foundation, Nashik
}

\begin{abstract}
In this paper research study has been made on the computational testing of wear rate for different materials (Cu, ss410 and Al) under the different condition of load applied, Speed and time. The set up of pin on disc tribometer has been used to study the wear rate of materials. The experiments has been performed on a group of specimens under different cases of times (5 to 15) minutes, and under different loads (3 to 7) Kg, and different speeds (500 to 1100)rpm the set up is connected with Data Acquisition System which gives wear rate of material computationally. By fixing any two parameters with one variable parameter experiment is performed [2]. Graphical representation of wear rate along with friction force and coefficient of friction is given by WINDUCOM software and the results will show the wear rate relation with (time, speed and load) and the comparisons of one material with other materials
\end{abstract}

Keywords: Wear, ss410, copper, Al, hardened steel, speed

\section{INTRODUCTION}

Wear is a loss of material obtained at contacting surfaces of material having relative motion between them. When two materials comes in contact with each other friction force is applied on the surface, but friction is related to energy loss. Both friction and wear causes surface damage of material results reduce in reliability. A different type of wear occurs at different surfaces.

The main types of wear are [1]:

1) Abrasive Wear: This type of wear occurs due to presence of hard particles in contacting material or in lubricating layer.

2) Adhesive Wear: When two surfaces slides on each other and they are separated with lubricating film due to improper lubrication

3) Surface Fatigue: Wear cracks are in occurs due to mechanical tension in contacting body surfaces. In this paper adhesive wear is investigated at different conditions of time, speed and load applied.

\subsection{A Different Types of Materials Used in}

\section{Experiment are:}

Metals: Copper and Aluminum are the non ferrous metals which are most widely used for various applications in electrical, mechanical and computer also for household equipments. Metals have important properties such as good conductors of electricity, high heat transfer rate so their applications are wide.

Alloys: Alloys are nothing but combination of two or more different metals. Alloys are made to improve properties of parent metals for various applications.SS410 is alloy of ferrous metal Cast Iron.

\subsection{Properties of Copper, Aluminum and SS410 [8]:}

\subsubsection{Copper:}

1) It is soft malleable and ductile material with reddish brown appearance.

2) Specific gravity of the material is 8.9 and melting point is $1083{ }^{\circ} \mathrm{C}$.

3) Tensile strength varies from $150 \mathrm{MPa}$ to $400 \mathrm{MPa}$.

4) It is good conductor of electricity.

\subsubsection{Aluminum:}

1) It is white metal produced by electrical process from oxide (alumina).

2) It is light metal having specific gravity 2.7 and melting point $658^{\circ} \mathrm{C}$

3) Tensile strength of material varies from $90 \mathrm{MPa}$ to150MPa.

4) Metal is weak and soft in its pure form but when mixed with alloy it becomes hard and rigid.

\subsubsection{SS410:}

1) It is cast iron alloy with dusky appearance.

2) Its tensile strength is $450 \mathrm{Mpa}$.

3) Hardened for maximum heat and corrosion resistance.

\subsection{Wear Failure and its Effect:}

Definition [5]: If one surface is slide over another then the asperities come into contact and there is a possibility that wear can occur. 
Wear can occur in different moving machine element such as rotating shafts, brake, lathe, clutch pedal etc.

\section{Effects [1]:}

1) Wear affects on mechanical system or parts like pump shaft, IC engines, brakes and valves their efficiency, operation and reliability.

2) So that to achieve better reliability more focus is on moving parts like bearings seals, piston cylinder and other moving parts.

3) In system like braking mechanism small amount of wear causes failure of system.

\section{EXPERIMENTAL:}

Methods of wear testing [7]:

1-Optical method

2- Weighing method

3- Mechanical method

Set up for pin on disc apparatus: [3]
4- Radio tracer techniques (measurement of radioactive pick-up method.

\subsection{Mechanical Method}

Pin on disc tribometer [6]:

This is laboratory method of wear testing comes under mechanical method of testing of wear. For the testing on pin on disk apparatus the specimens were a pin with a rounded tip and circular disk which rotate as per given speed in its working range the position of flat circular disk is exactly perpendicular to test specimen. A pin is held against the disk. The test machine causes rotation of disk while pin is stationary. The sliding path is a circular with fixed wear track radius on the disk surface. The pin is pressed against the disk at a specified load with the help of an arm or lever and attached weights as per design.

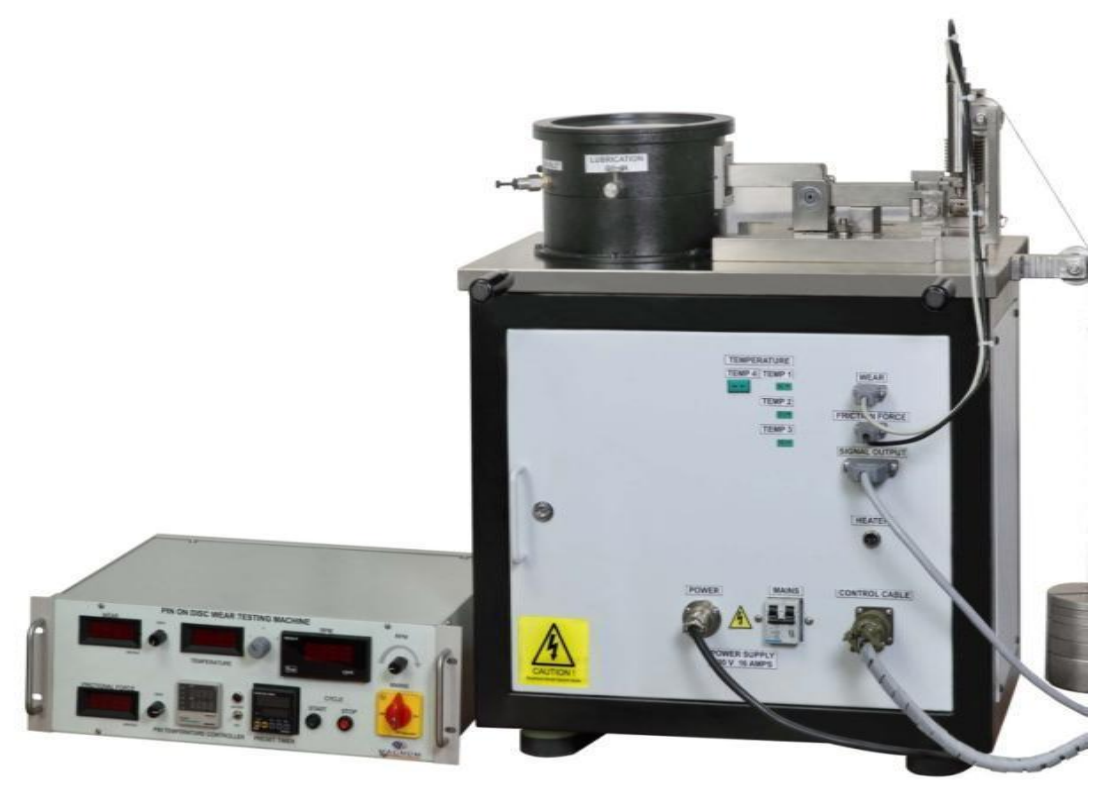

Fig: 1 experimental set up of pin on disc tribometer.

\subsubsection{Technical Specifications of Machine}

Table 1[3] specifications of machine

\begin{tabular}{|l|l|}
\hline Test parameter & Values \\
\hline Specimen & $\begin{array}{l}\text { Pin size:- } 10 \& 12 \mathrm{~mm} \\
\text { diameter 32 mm long Ball : } \\
\text { spherical ball } \varnothing 10\end{array}$ \\
\hline Wear disc size & $\begin{array}{l}\text { Diameter } 165 \mathrm{~mm}, 8 \mathrm{~mm} \\
\text { Thick }\end{array}$ \\
\hline $\begin{array}{l}\text { Wear track } \\
\text { Diameter }\end{array}$ & Min:50mm,Max:500 \\
\hline Disc rotation & Min:200rpm,Max:2000rpm \\
\hline Normal load & Min:5N,Max:200N \\
\hline Friction force & Min:0N,Max:200N \\
\hline
\end{tabular}




\subsubsection{Testing Conditions:}

Wear track diameter: $100 \mathrm{~mm}$

Diameter of pin: $10 \mathrm{~mm}$

\section{RESULT AND DISCUSSION:}

3.1 Constant Load: 3kg; Constant Time: $5 \mathrm{~min}$; Speed is Variable.

Table: 2

\begin{tabular}{|l|l|l|l|l|}
\hline \multirow{2}{*}{$\begin{array}{l}\text { Sr. } \\
\text { No }\end{array}$} & Sped in & \multicolumn{3}{|l|}{ Wear rate in micrometer } \\
\cline { 3 - 5 } & Rpm & SS410 & Al & Cu \\
\hline 1 & 600 & 1148 & 895 & 584 \\
\hline 2 & 900 & 1492 & 1774 & 379 \\
\hline 3 & 1100 & 2218 & 1283 & 507 \\
\hline
\end{tabular}

Test Result for SS410

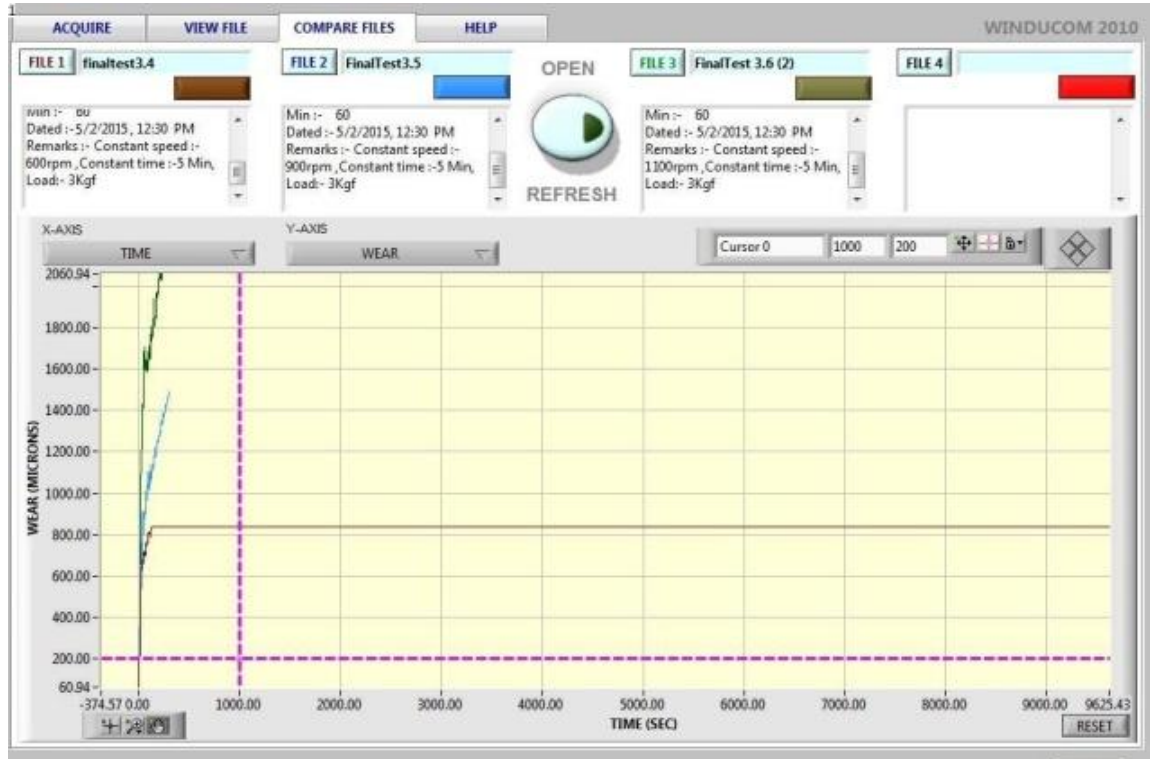

Graph 1 Wear rate of SS410

\section{Test Result for $\mathrm{AL}$}

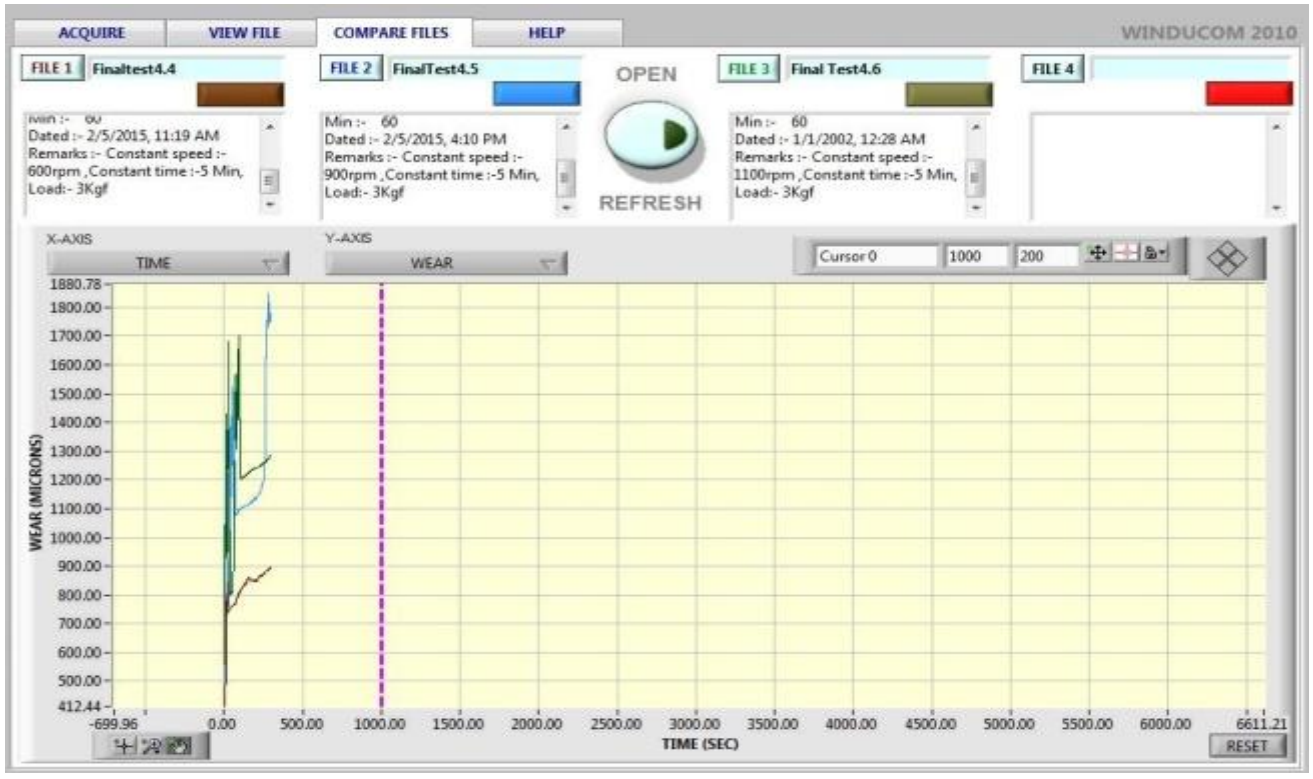

Graph 2 Wear rate of $\mathrm{Al}$ 


\section{Test Result for CU}

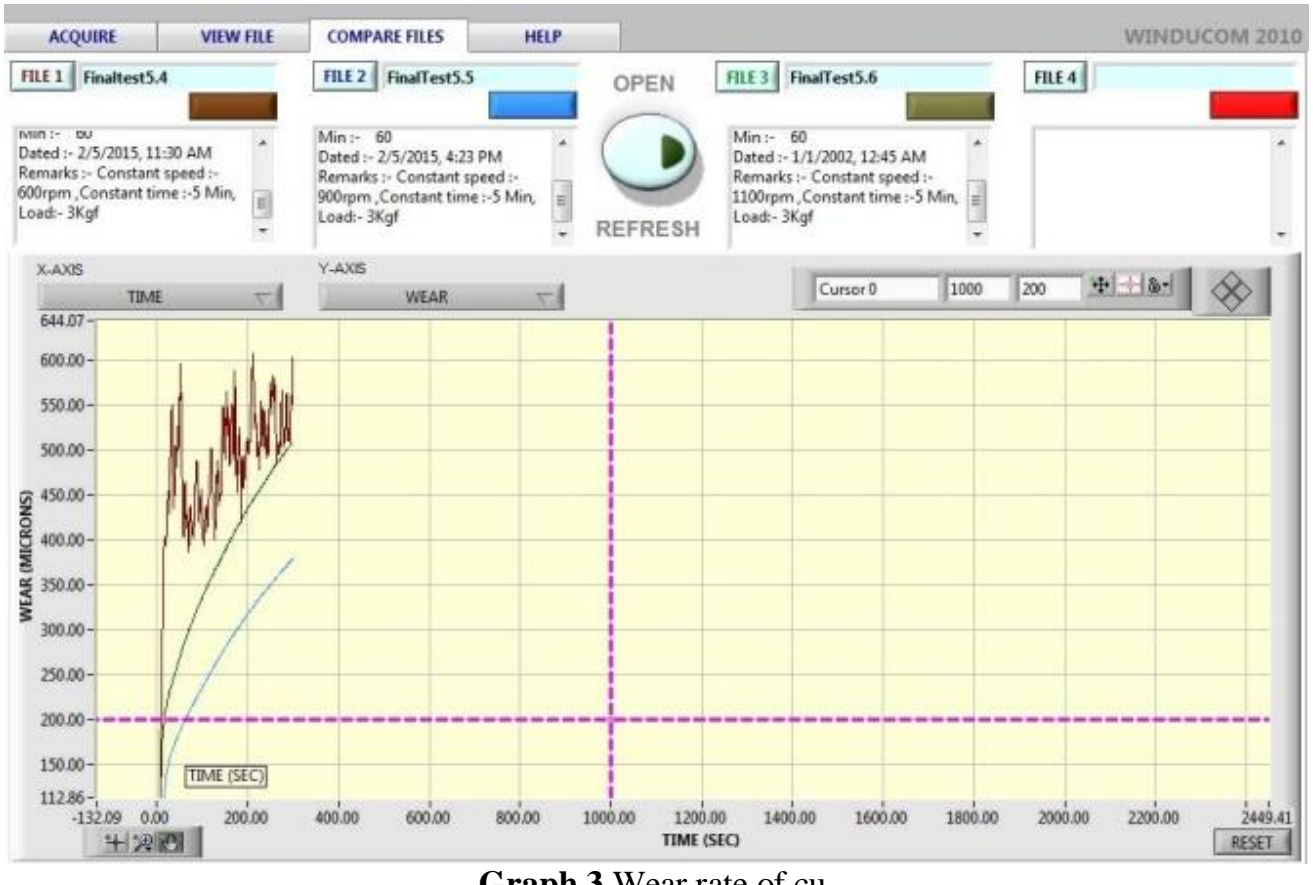

Graph 3 Wear rate of cu

\subsection{Constant Speed: 500rpm; Constant Time: $5 \mathrm{~min}$; Load is Variable}

Table: 3

\begin{tabular}{|l|l|l|l|l|}
\hline \multirow{2}{*}{$\begin{array}{l}\text { Sr. } \\
\text { No }\end{array}$} & \multirow{2}{*}{$\begin{array}{l}\mathrm{kg} \\
\text { ng in }\end{array}$} & \multicolumn{4}{|l|}{ Wear rate in micrometer } \\
\cline { 3 - 5 } & $\mathrm{SS} 410$ & $\mathrm{Al}$ & $\mathrm{Cu}$ \\
\hline 1 & 3 & 512 & 2366 & 294 \\
\hline 2 & 5 & 1177 & 2205 & 249 \\
\hline 3 & 7 & 1675 & 1129 & 920 \\
\hline
\end{tabular}

\section{Test Result for SS410}

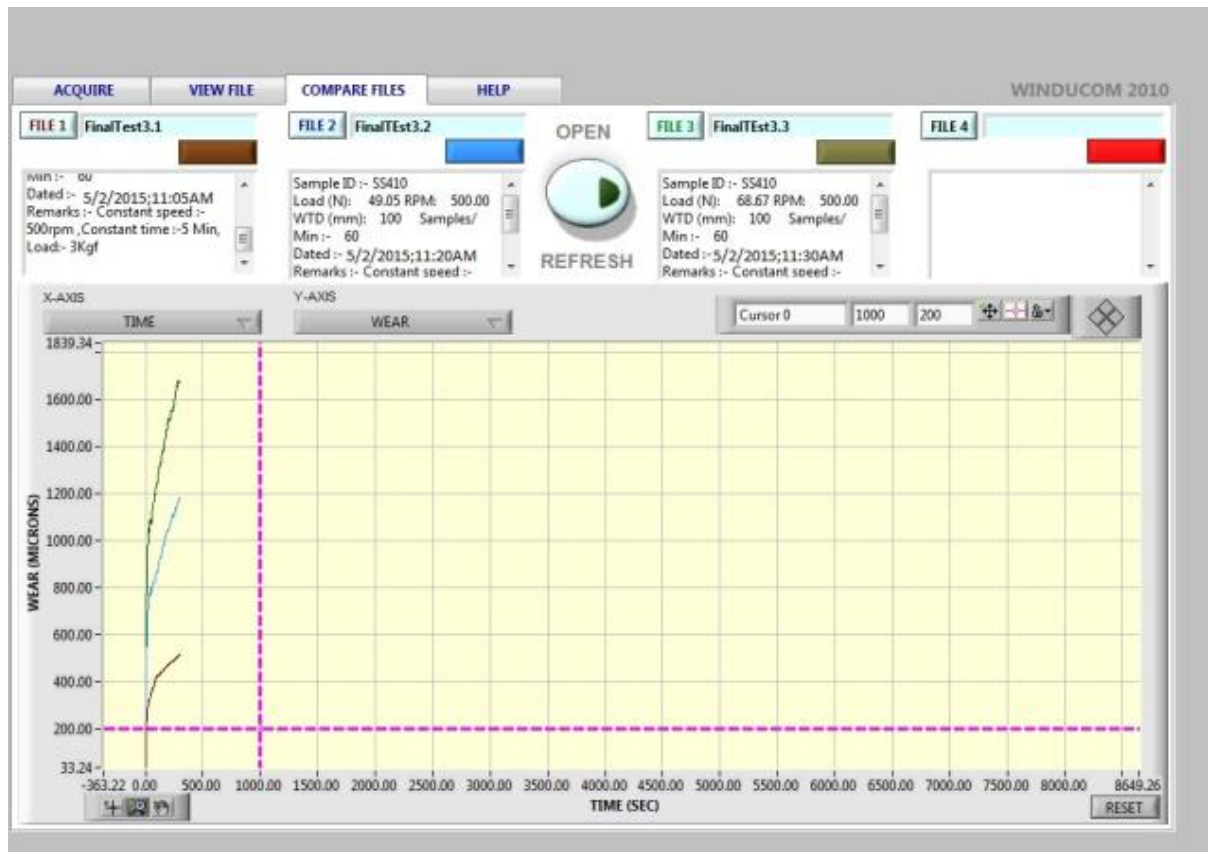

Graph 4 Wear rate of SS410 


\section{Test Result for $\mathbf{A L}$}

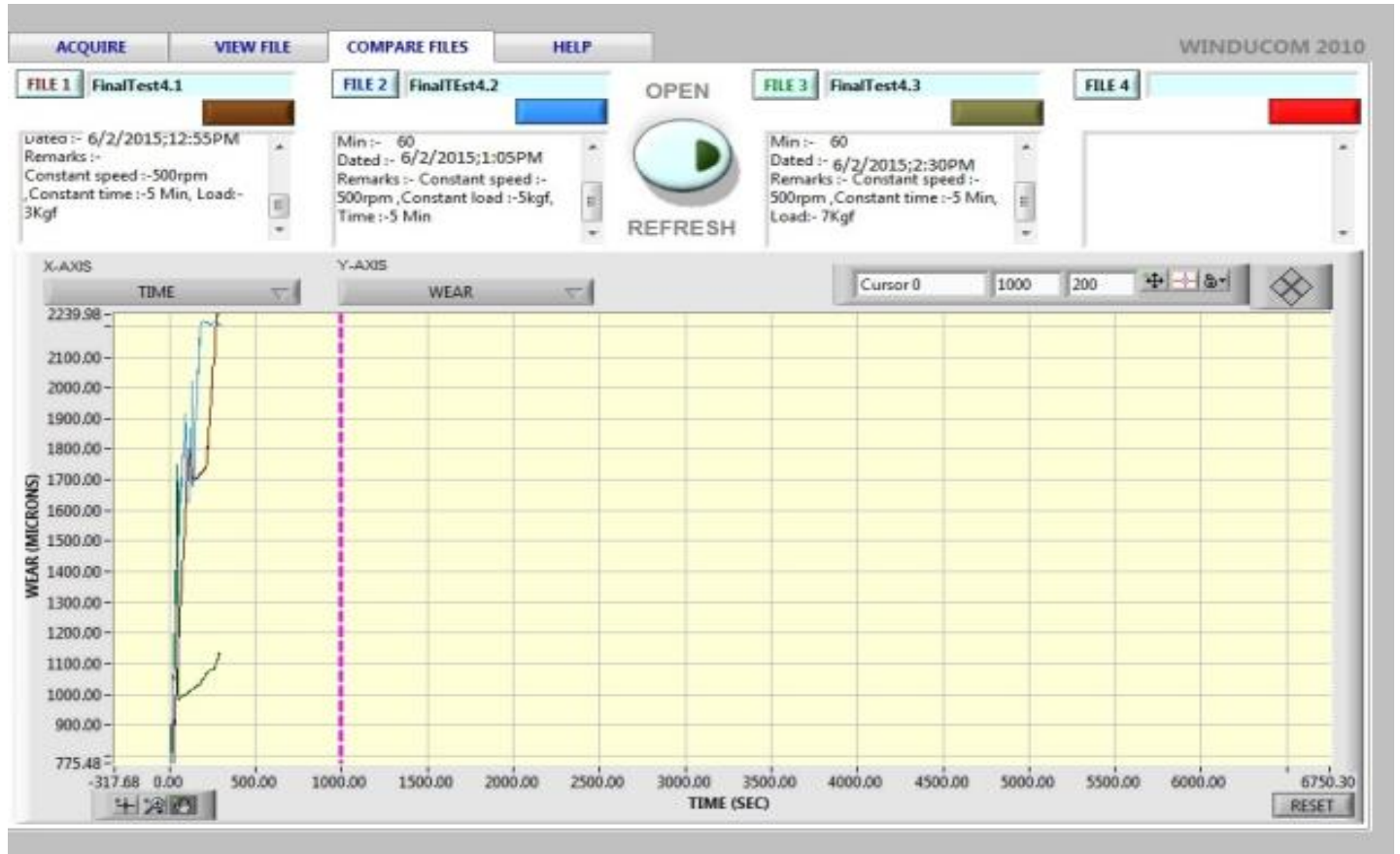

Graph 5 Wear rate of AL

\section{Test Result for CU}

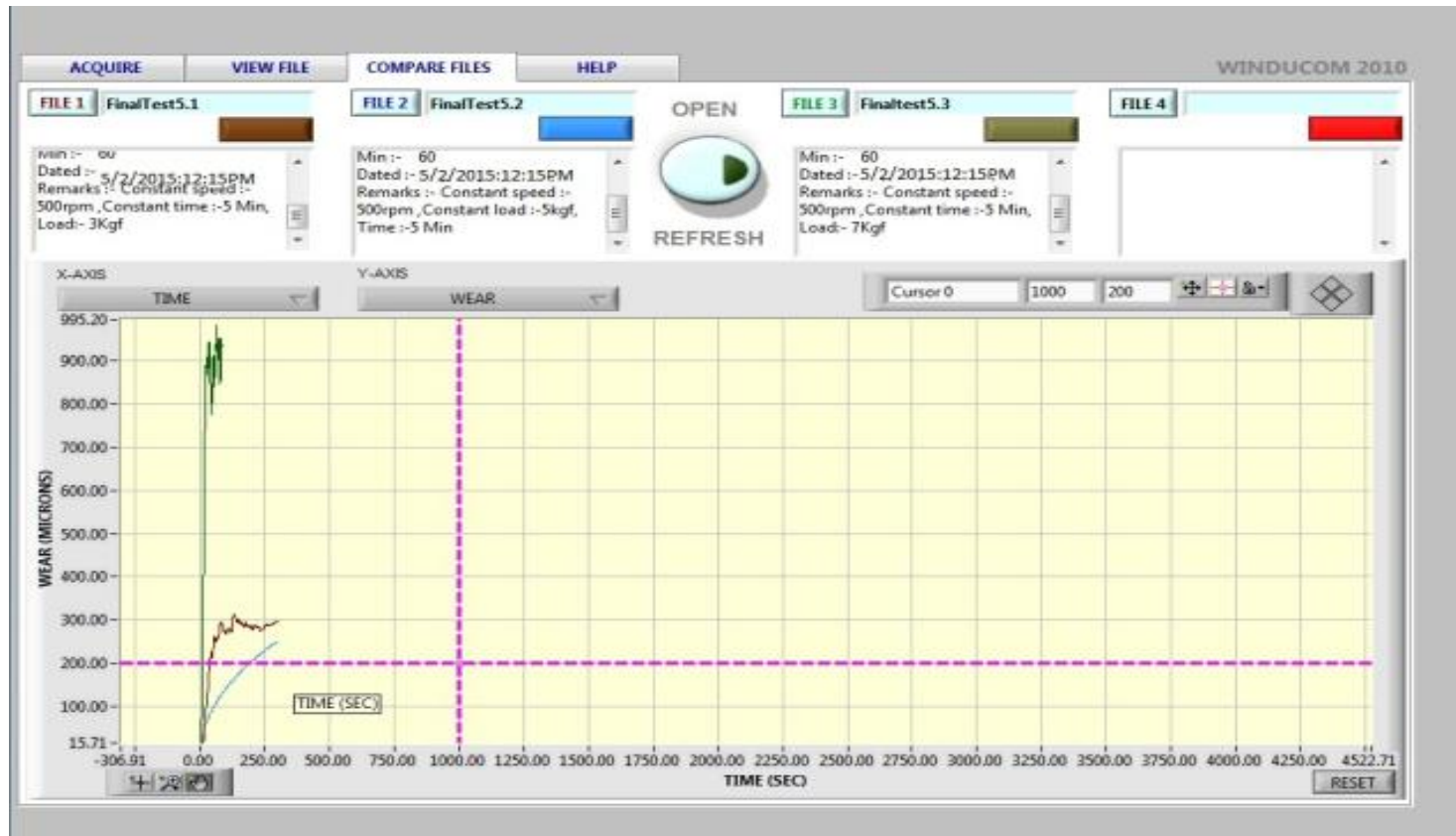

Graph 6 Wear rate of $\mathrm{Cu}$

\subsection{Constant Load: $3 \mathrm{~kg}$; Constant Time: $5 \mathrm{~min}$; Time is Variable.}

Table: 4

\begin{tabular}{|l|l|l|l|l|}
\hline Sr. & Time in & \multicolumn{3}{|l|}{ Wear rate in micrometer } \\
\cline { 3 - 5 } No & Min & SS410 & Al & Cu \\
\hline 1 & 5 & 512 & 2366 & 294 \\
\hline 1 & 10 & 1037 & 2241 & 224 \\
\hline 2 & 15 & 942 & 910 & 461 \\
\hline
\end{tabular}




\section{Test Result for SS410}

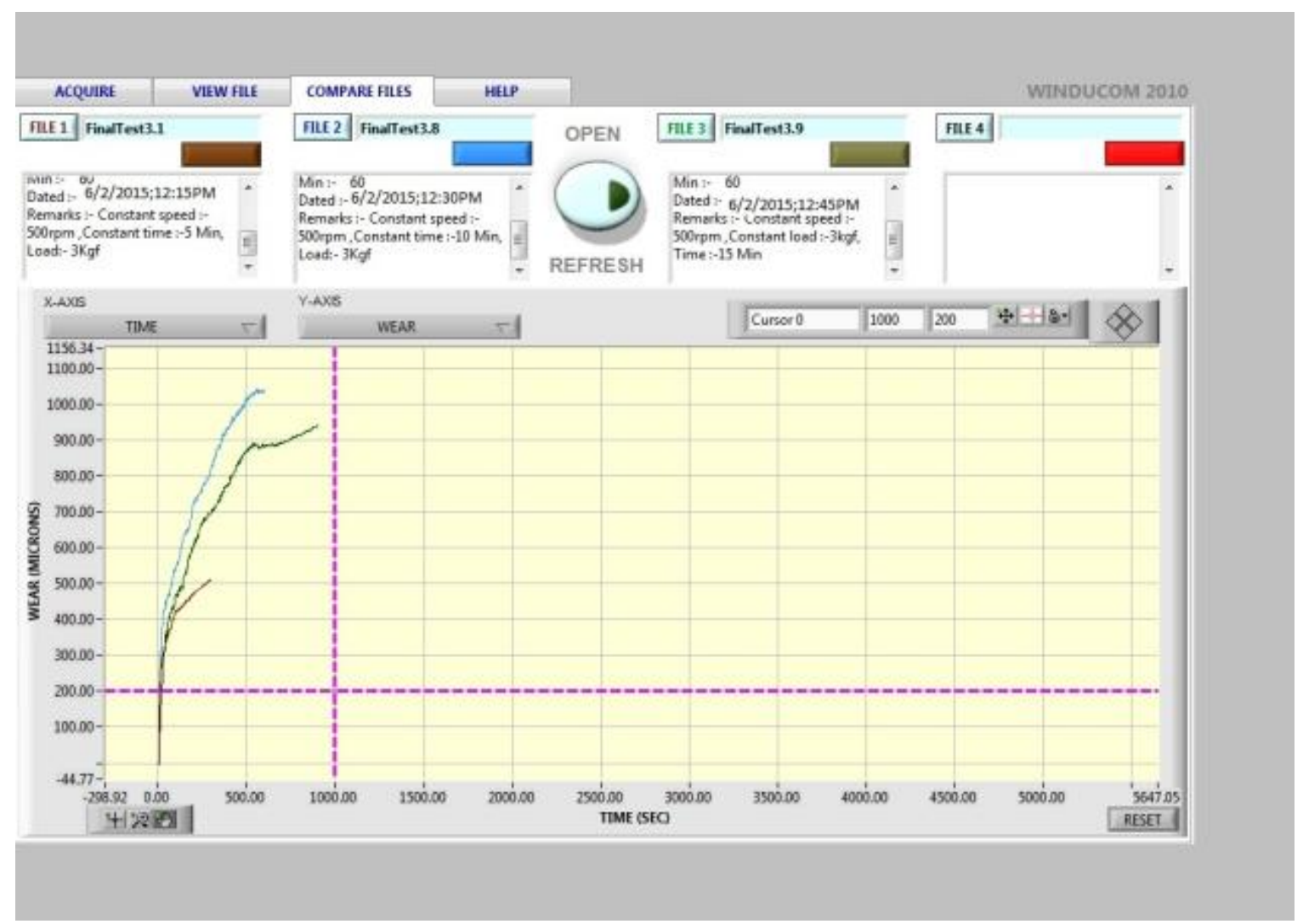

Graph 7 Wear rate of SS410

\section{Test Result for AL}

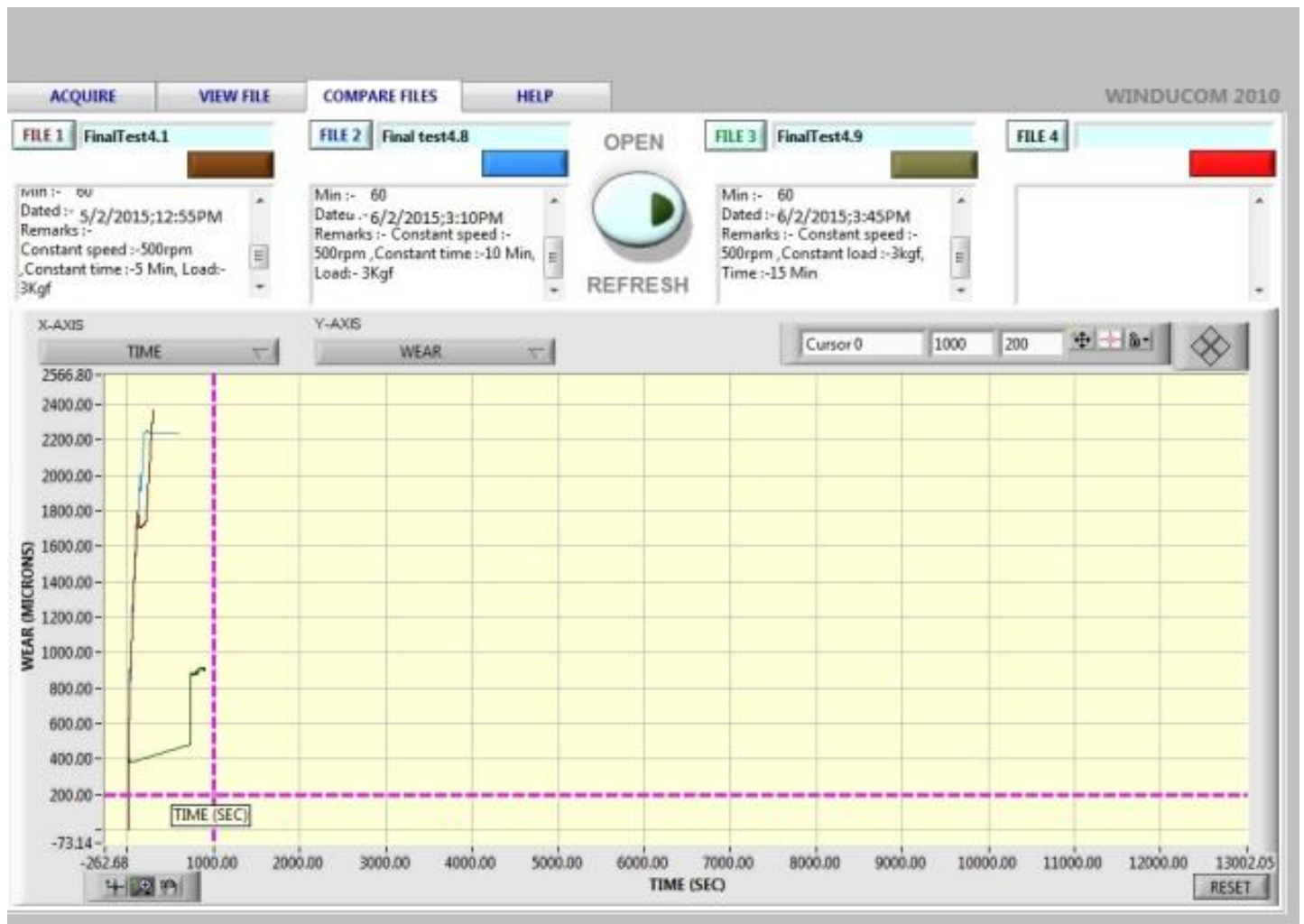

Graph 8 Wear rate of Al 


\section{Test Result for CU}

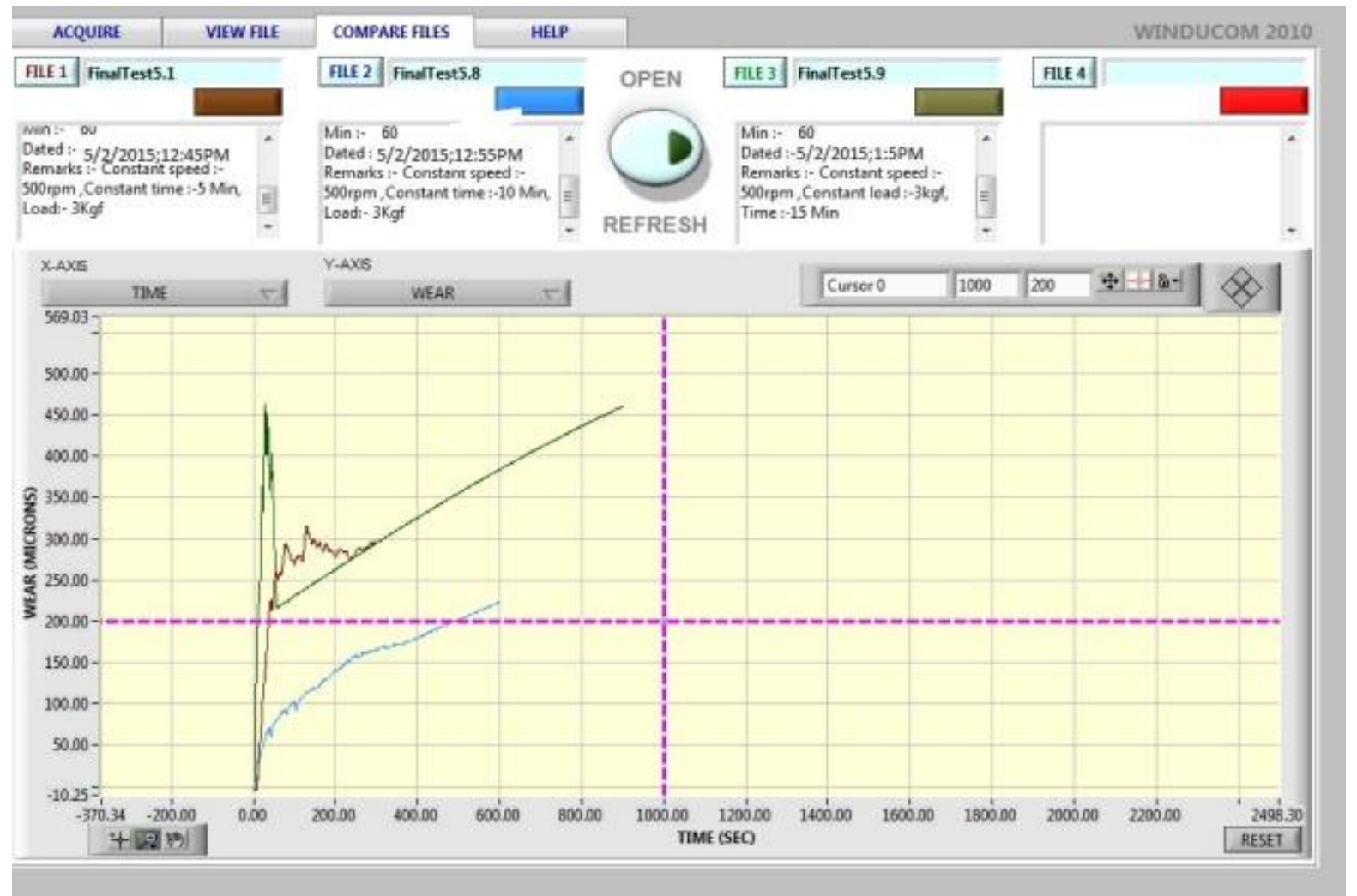

Graph 9 Wear rate of $\mathrm{Cu}$

\section{CONCLUSION}

1) For variable speed range, SS410 shows increase in wear rate corresponding to speed, while $\mathrm{Al}$ shows first increase in wear but after increasing in speed wear rate decreases.

2) Experimental results shows the $\mathrm{Al}$ and SS410 have maximum wear rate than Copper when any parameter is vary

3) Copper has better wear resistance property than $\mathrm{Al}$ and $\mathrm{SS} 410 . \mathrm{Cu}$ can used instead of these two in some applications.

4) Wear rate of $\mathrm{Al}$ decreases with increase in time hence it can be used for long time operation with constant speed and load.

5) Wear rate of Copper At first decreases with respect to time but it rapidly increases as time further increases.

6) All the Graphs of SS410 give smooth curves of wear rate while distinguish patterns of curves can observed in $\mathrm{Cu}$ and Al.

7) Maximum value of wear is given by $\mathrm{Al}$ at $500 \mathrm{rpm}, 3 \mathrm{~kg}$ load and 5min time while SS410 gives exactly opposite result that is shows lowest wear rate.

\section{REFERENCES:}

[1] Friction, wear, lubrication. A textbook in Tribology K.C Ludema Professor of Mechanical Engineering, The University of Michigan Ann Arbor CRC Press Boca Raton New York London Tokyo.
[2] Effect of loads, sliding speeds and times on the wear rate for different materials. Hani Aziz Ameen1, Khairia Salman Hassan2 and Ethar Mohamed Mhdi Mubark.

[3] Experimental lab manual on tribnology mechanical department NDMVP College.

[4] Y.Tsyu, Microstructure of Wear, Friction and solid lubrication, Tech. Reproof Mechanical Eng. Lab. Japan, Volume.3, No.81, 1975.

[5] Sliding friction and wear behaviour of polytetrafluoroethylene and its composites under dry conditions H. Unal a, A. Mimaroglu b, * U. Kadıoglu a, H. Ekiz a Faculty of Technical Education, University of Sakarya, Esentepe Kampusu, Adapazari, Turkey.

[6] TRIBOLOGICAL BEHAVIOUR OF EN8 STEEL IN PRESENCE OF ZnO NANOFLUID Dr.Sanjay Shrivastava1, Rupesh Kumar Malviya2, Manish Verma3Dept of Mech Engg.

[7] Wear study on SS316 L.Ti-6-Al$4 \mathrm{~V}, \mathrm{PEEK}$, Polyurethane and Alumina used as Biomaterial.

[8] A book of "Material science and metallurgy" O.P. Khanna. 